\title{
Análise da Presença de Fungos Totais e Aflatoxigênicos em Amostras Industrializadas de Aveia em Flocos e Farinha de Aveia.
}

Laury Francis Costa (I), Cleciana Maristela de Souza (II), Idjane

Santana de Oliveira (II), Edvane Borges da Silva (I)

(I) UFPE - Universidade Federal de Pernambuco (Av. Prof. Moraes Rego, 1235 - Cidade Universitária- Recife - PE - CEP: 50670-901), (II) CAV-UFPE - Centro Acadêmico de VitóriaUFPE (Rua Alto do Reservatório, S/N - Bela Vista,CEP:55608-680,Vitória de Santo Antão)

\section{Resumo}

Introdução: A aveia é cereal bastante nutritivo, contendo minerais, proteínas, vitaminas, carboidratos e fibras, e muito usado na alimentação devido ao poder benéfico de sua fibra, que está relacionada ao bom funcionamento intestinal, e manutenção dos níveis equilibrados de colesterol total e LDL-colesterol. O armazenamento dos produtos industrializados do processamento da aveia é crucial para evitar a ingestão de fungos e micotoxinas pelos consumidores. O trabalho objetivou avaliar a qualidade micológica de flocos, farinha e farelo de aveia. Materiais e métodos: Foram analisadas 13 amostras de aveia, incluindo aveia em flocos grossos, finos, farinha e farelo de aveia, de 5 marcas, obtidas de supermercados e casas de venda de produtos naturais. As amostras foram submetidas ao método de diluição e semeadas em meio de cultura DG18 e AFPA, incubadas a temperatura ambiente por 3 dias. Em seguida foi realizada a contagem do número de colônias fúngicas, e identificação do gênero do fungo contaminante. Resultados: As amostras 7, 8, 9, 10 (marca 4) e 12 e 13 (marca 5) apresentaram 100\% de ausência de crescimento fúngico, o que já era esperado pois são marcas comercializadas bastante conhecidas. As outras amostras apresentaram crescimento fúngico nas três diluições, com incontáveis colônias e os gêneros de fungos encontrados foram apenas Aspergillus sp. seção niger e flavi e Penicillium sp. As amostras 2 e 11 , referentes as marcas 1 e 2, respectivamente, apresentaram

\footnotetext{
Referência:

Laury Francis Costa, Cleciana Maristela de Souza, Idjane Santana de Oliveira, Edvane Borges da Silva.Análise da Presença de Fungos Totais e Aflatoxigênicos em Amostras Industrializadas de Aveia em Flocos e Farinha de Aveia.. In: Anais do $12^{\circ}$ Congresso Latinoamericano de Microbiologia e Higiene de Alimentos - MICROAL 2014 [= Blucher Food Science Proceedings, num.1, vol.1]. São Paulo: Editora Blucher, 2014. DOI $10.5151 /$ foodsci-microal-060
} 
crescimento fúngico positivo no meio AFPA, ou seja, produtor de aflatoxina. Não houve crescimento de fungos aflatoxigênicos nas outras amostras analisadas. As amostras que apresentaram maior contaminação foram: 6 (da marca 3) com $400 \mathrm{UFC} / \mathrm{ml}$, na terceira diluição, 3 e 11 ( marca 2), com aproximadamente $40 \mathrm{UFC} / \mathrm{ml}$ na primeira diluição. Conclusão: $54 \%$ das amostras estavam contaminadas com fungos e $15 \%$ com fungos aflatoxigênicos, indicando risco para a saúde humana.

Palavras-Chave: aveia, aflatoxinas, Aspergillus Agência de Fomento: CAPES 